\title{
A preliminary study investigating effects of oral monensin sodium in an enteric Mycobacterium avium ssp. paratuberculosis infection model of calves
}

\author{
K. J. Stinson, ${ }^{1}$ T. F. Duffield, ${ }^{2}$ D. F. Kelton, ${ }^{2}$ M. M. Baquero, ${ }^{1}$ and B. L. Plattner ${ }^{1 *}$ \\ ${ }^{1}$ Department of Pathobiology, Ontario Veterinary College, University of Guelph, Guelph, ON N1G 2W1, Canada \\ ${ }^{2}$ Department of Population Medicine, Ontario Veterinary College, University of Guelph, Guelph, ON N1G 2W1, Canada
}

\begin{abstract}
Mycobacterium avium ssp. paratuberculosis (MAP) is the causative agent of Johne's disease, an enteric infection of ruminants that causes significant economic burden for dairy and beef producers. Efforts to control MAP in endemic herds typically focus on herd management practices such as limiting exposure or early culling of infected animals and, occasionally, vaccination. The ionophore monensin sodium may have protective effects against MAP both in vivo and in vitro; however, this has not been thoroughly evaluated experimentally. Using a direct intestinal MAP challenge model, we have observed similarities regarding persistence of MAP in tissues and apparent resilience to infection compared with experimental oral infection or natural disease. Here we sought to investigate the effects of oral monensin supplementation in experimentally MAP-infected calves. We examined the persistence of MAP in the intestinal tissues, MAP-induced intestinal inflammation, fecal MAP shedding, and seroconversion using a commercial serologic assay. Monensin-supplemented MAP-infected calves demonstrated evidence for resilience to MAP infection earlier in this study compared with monensin-free MAP-infected calves. However, statistical modeling did not identify a significant effect of monensin on outcomes of infection, and more work is required to understand how monensin affects early tissue colonization of MAP in calves.

Key words: paratuberculosis, Johne's disease, cattle, monensin
\end{abstract}

\section{INTRODUCTION}

Johne's disease (JD), a chronic enteritis of ruminants, has a significant economic impact on North American dairy and beef production (McKenna et al.,

Received November 12, 2018.

Accepted June 12, 2019.

*Corresponding author: bplattne@uoguelph.ca
2006; Tiwari et al., 2006). Johne's disease is caused by the bacterium Mycobacterium avium ssp. paratuberculosis (MAP), which is ingested by young animals via contaminated feces, colostrum, or milk. Mycobacterium avium ssp. paratuberculosis invades the intestinal mucosa of the distal ileum overlying Peyer's patches and survives within resident macrophages (Sweeney et al., 2012). Infected animals may show no outward evidence of infection for several years (subclinical JD); however, MAP is sporadically shed in their feces, which perpetuates and disseminates the pathogen to susceptible herdmates (Sweeney, 2011). A subset of infected animals may develop clinical JD, which is characterized by inflammation and thickening of the small intestinal mucosa, leading to chronic malabsorptive diarrhea, dehydration, wasting, and often death, with MAP increasingly shed in their feces (Sweeney, 2011; Sweeney et al., 2012).

Control of JD on farms is largely focused on surveillance techniques seeking to identify MAP-infected animals and remove them from the herd (Collins, 1994; Garry, 2011). Other management practices, such as separating susceptible calves from shedders of MAP, also play a role in prevention of MAP exposure; however, JD remains very challenging to control, particularly in endemically infected herds (Bastida and Juste, 2011; Garry, 2011). Thus far, attempts to develop an efficacious JD vaccine have been variably successful. Although vaccines reduce fecal MAP shedding and slow disease progression, they do not prevent new infections (Uzonna et al., 2003; Juste et al., 2009; Sweeney et al., 2009). Vaccination also causes false-positive reactions in commercial serologic tests for MAP (ELISA), which are commonly used in diagnostics and herd management around the world (Köhler et al., 2001; Muskens et al., 2002; Stabel et al., 2011).

One control strategy that has not been heavily investigated is the use of chemoprophylactic or antimicrobial agents for preventive or therapeutic purposes. The ionophore monensin sodium has been studied in vivo and in vitro for its hypothesized beneficial effects 
against MAP. Monensin is widely used in North American ruminants for control of coccidiosis in calves and for feed efficiency and ketosis prevention in dairy cattle with no milk or meat withdrawal time (McDougald, 1978; Goodrich et al., 1984; Duffield et al., 1999a,b). Monensin is labeled in Canada as a controlled-release capsule for the reduction of fecal MAP shedding in mature cattle from high-risk herds as part of a multicomponent JD control program (Kexxtone, Elanco Animal Health Canada, Guelph, ON, Canada). Data regarding the efficacy of oral monensin as therapeutic or prophylactic against MAP-associated disease in cattle have been reviewed extensively (Fecteau and Whitlock, 2011). Mycobacterium avium ssp. paratuberculosis is susceptible to monensin in vitro, with a dose-dependent inhibitory effect on MAP grown in liquid and radiometric culture systems (Brumbaugh et al., 2004; Greenstein et al., 2009). Monensin has also been shown to provide a prophylactic protective effect in mice experimentally inoculated with MAP via intraperitoneal injection (Brumbaugh et al., 1992, 2004). In the mouse model, there was significant reduction of hepatic granulomas in monensin-supplemented MAPinfected mice compared with control mice. In naturally MAP-infected cattle, oral monensin administration was associated with reduced severity of histologic lesions and decreased fecal MAP shedding, suggesting that monensin slowed or reversed the progression of disease (Brumbaugh et al., 2000; Hendrick et al., 2006b). Adult dairy cows receiving oral monensin were less likely to test positive for MAP antibodies by ELISA, suggesting that monensin is also immune modulatory (Hendrick et al., 2006a). Despite these data suggesting beneficial effects of monensin during various aspects of intestinal MAP infection, no studies of the effects of oral monensin during experimental MAP infection of calves have been published.

Data using the direct intestinal MAP inoculation model suggest that many calves are resilient to MAP infection, which is most likely due to early clearance of the pathogen (Stinson et al., 2018); this is consistent with naturally occurring JD and a long-term oral MAP-exposure model (Begg et al., 2018; de Silva et al., 2018). In this study, we investigated the effects of oral monensin supplementation during the early post-MAPexposure period in the same model. We compared the results of several routine laboratory tests commonly used for diagnosis of JD, including histologic intestinal lesions, fecal MAP shedding, and serum MAP-specific antibody responses, from monensin-supplemented calves and monensin-free calves following experimental direct intestinal MAP inoculation. We hypothesized that monensin-supplemented calves would have increased resilience against early MAP colonization compared with monensin-free calves based on decreased severity of histologic lesions, reduced frequency of fecal MAP shedding, and decreased serum MAP-specific antibody responses. Monensin is not approved for control of MAP in calves; however, this study is relevant to field control of MAP because calves are routinely administered oral monensin sodium for alternate approved reasons.

\section{MATERIALS AND METHODS}

\section{Animal Infection Model}

The animal infection model was performed as previously described (Stinson et al., 2018). Briefly, fortyeight 3- to 4-wk-old castrated male Holstein calves were obtained from the Elora dairy research and teaching farm (University of Guelph, Guelph, ON, Canada). At the time of this study, the source farm was considered free of JD based on routine screening of animals by ELISA and fecal culture as part of a voluntary surveillance program. The monensin-supplemented calves (n $=24$ ) in this study were 1 cohort of the larger block study design that included previously published data on the monensin-free calf cohort $(\mathrm{n}=24$; Stinson et al., 2018). All methods described are identical between both cohorts with the exception of monensin supplementation. Animal group sizes were selected based on power analysis and previous work with this model, in which we observed consistent intestinal MAP infection of calves with minimal interanimal variance at $12 \mathrm{wk}$ postinoculation (wpi; Plattner et al., 2011).

Monensin-supplemented calves $(\mathrm{n}=24)$ were randomly assigned to 1 of 4 groups of 6 animals each and acclimated to the facility for $1 \mathrm{wk}$. Groups contained 4 MAP-exposed and 2 unexposed control animals each and were housed in an animal biosafety level-2 unit in pairs; control animals were housed separately from MAP-exposed calves. The MAP-exposed calves were individually inoculated with $10^{9} \mathrm{cfu}$ of live MAP (prepared as previously described) by subserosal injection into the antimesenteric surface of the distal ileum approximately $5 \mathrm{~cm}$ proximal to the ileocecal valve (Plattner et al., 2011; Stinson et al., 2018). Sterile India ink was injected immediately proximal to the site of inoculation to identify the injection site and draining lymph nodes on necropsy. Feces were collected pre-exposure and biweekly thereafter, and serum was collected pre-exposure and monthly thereafter. Groups of animals were killed at $4,12,20$, or 28 wpi, and complete postmortem examinations were performed on each calf. Tissues were collected from the ileocecal valve (tissue A), 3 sections of the distal ileum with 5 $\mathrm{cm}$ of separation (tissues B, C, and D, each taken 5 $\mathrm{cm}$ proximal to the previous section), and the draining 
ileocecal lymph node (tissue E). Serial sections of tissue were snap frozen in liquid nitrogen for future DNA extraction and fixed in 10\% neutral buffered formalin. Uninoculated calves were housed separate from MAPinoculated calves, and monensin-supplemented calves were housed separate from monensin-free calves. All animal work was performed under an approved animal utilization protocol (University of Guelph AUP no. 1390), reviewed by the University of Guelph Animal Care Committee.

\section{Oral Monensin Supplementation}

Animals were supplemented with oral monensin sodium beginning 1 wk before surgical MAP exposure and continuing throughout the duration of the study. For calves before weaning, liquid monensin sodium (Rumensin Max, Elanco Animal Health, Manukau, New Zealand; $50 \mathrm{mg} /$ head per day) in water was administered orally once daily to each calf by dose syringe. At 6 wpi, calves were weaned and transitioned to a granular formulation of monensin sodium premix (Rumensin, Elanco Animal Health Canada; $200 \mathrm{~g} / \mathrm{kg}$ ) in a pelleted calf starter grain ration at a dose calculated to deliver $22 \mathrm{mg} / \mathrm{kg}$ of BW on a DMI basis per day, which is the approved dose for oral monensin sodium for control and prevention of coccidiosis in dairy cattle, split into a morning and an evening feeding. Medicated calf starter was administered to calves in individual feeding buckets, with the calves haltered and hitched to separate points in the room during feeding. This ensured that the calves were physically separated and did not share medicated grain and that each calf consumed the daily dosage of medicated grain.

\section{Tissue Histology}

After $24 \mathrm{~h}$ of fixation in formalin, all tissue sections were trimmed, paraffin embedded, sectioned at $5 \mu \mathrm{m}$, stained with hematoxylin and eosin, and coverslipped. All sections were examined histologically for the presence of granulomatous inflammatory lesions attributable to MAP infection. Serial sections of all tissues were also stained per standard protocol with Ziehl-Neelsen (ZN) staining for direct detection of acid-fast bacilli (AFB) within the tissue as a positive-negative result. All staining was performed by the histology laboratory personnel at the Animal Health Laboratory, University of Guelph. Histologic lesions were blindly scored as previously described on a scale of 0 to 5 (Stinson et al., 2018). Briefly, a score of 0 was assigned if no inflammation was present, a score of 1 was assigned for lesions of focal granulomatous inflammation (mild lesions), a score of 2 or 3 was given to tissues with multifocal granulomatous inflammation (moderate lesions), and a score of 4 to 5 was given to tissues with coalescing granulomatous inflammation (severe lesions).

\section{Molecular Detection of MAP}

Detection of MAP in tissues and feces was performed as previously described (Stinson et al., 2018). Briefly, tissue DNA was extracted from $100 \mathrm{mg}$ of flash-frozen tissue (tissues A-E, described above) using the Qiagen DNEasy Blood and Tissue kit (Qiagen Canada, Toronto, ON, Canada) with the protocol modified for increased volume of tissue. Any tissues where MAP was not detected by PCR were re-extracted and reprocessed. Fecal DNA was extracted from $1 \mathrm{~g}$ (wet weight) of feces using a pretreatment step designed to reduce background fecal microbiota before extraction using a Norgen Biotek Stool DNA Extraction Kit (Norgen Biotek, Thorold, ON, Canada). The PCR amplification was performed using a Quanta PCR Toughmix II (Quanta Biosciences, Beverley, MA) in a heminested reaction targeting the IS900 gene.

\section{Serum ELISA}

The MAP-specific antibodies were detected using an Idexx MAP antibody ELISA assay (Idexx Canada, Markham, ON, Canada), a commercially available assay widely used in the field. Samples were scored as a sample:positive control ratio, where a ratio below 0.45 was considered negative, between 0.45 and 0.55 was considered suspect, and above 0.55 was considered positive, according to the manufacturer's guidelines.

\section{Animal Infection Status}

Animals were classified as exposed, infected, diseased, or resilient based on the classification scheme developed by Whittington et al. (2017). By this classification system, animals that underwent surgical MAP inoculation were considered MAP exposed. The MAP-exposed animals with detectable MAP organisms in intestinal tissue based on PCR or ZN detection were considered MAP infected. The MAP-infected animals with moderate or severe granulomatous inflammation (scores $>2$, as outlined above) were considered diseased. Last, MAP-exposed animals with no detectable MAP in tissue at the time of killing were considered MAP resilient.

\section{Statistical Inference}

Statistical inference was performed using $\mathrm{R}$ Studio as mixed-effect logistic regression modeling (PCR and 
ZN data) or cumulative link mixed-effect modeling (histologic lesion scores). Logistic regression modeling was performed using the lme4 package's "glmer" function with time point as a fixed effect and animal ID and tissue section as nested random effects (Bates et al., 2015). Cumulative link mixed-effect modeling was performed using the ordinal package's "clmm" function (Christensen, 2019). The general formula for this was FACTOR $\sim$ time point $+(0+$ time point|animal/ tissue), where FACTOR represents PCR, ZN, or hematoxylin and eosin data. For analysis of the effects of monensin, the formula was adjusted to FACTOR $\sim$ time point + monensin $+(0+$ time point|animal/tissue), and the data from our previous article examining this model in monensin-free calves were included. Main effects for histologic lesion scores, PCR, and ZN data were reported as odds ratios with corresponding $95 \%$ confidence interval $(\mathbf{C I})$, and a significance level of $\alpha$ $=0.05$ was used.

\section{RESULTS}

\section{Gross Lesions}

During postmortem examination, India ink was observed in tissue approximately $5 \mathrm{~cm}$ proximal to the ileocecal valve and within the draining ileocecal lymph node of MAP-exposed calves, confirming initial appropriate placement of the MAP inoculum. Fibrous adhesions were occasionally observed between the serosal surface of the ileum at the site of injection and the omentum. No gross pathologic changes consistent with JD were observed in any MAP-exposed animals during postmortem examination. One MAP-exposed calf assigned to the 20-wpi group (calf ID 1228) developed severe pneumonia 3 wk after surgical MAP exposure and was killed due to lack of response to treatment.

\section{Histologic Lesions and Scoring}

Histologic lesion scores and AFB observed by ZN staining are shown in Figure 1 and summarized in Table 1. Unexposed control calves had no detectable granulomatous inflammation in intestine or lymph node sections and no AFB detected in $\mathrm{ZN}$-stained tissue segments. Granulomatous inflammation in the intestine of MAP-exposed calves was observed primarily within the lamina propria, and only occasional lesions were noted within the submucosa or the serosa. The maximum histologic lesion score for inflammation attributable to MAP observed in any tissue section for monensin-supplemented calves was 3 .

At 4 wpi, MAP-exposed calves had a median lesion score of 1 (range: $0-3$ ), with 2 tissues scoring at the maximum lesion score of 3 . Lesions were observed in $60 \%(12 / 20)$ of tissue segments, with 5 mild lesions and 7 moderate lesions, and AFB were observed in $30 \%$ $(6 / 20)$ of ZN-stained tissue segments.

At 12 wpi, MAP-exposed calves had a median lesion score of 0 (range: $0-3$ ), with 3 tissues scoring at the maximum lesion score of 3 . Lesions were observed in $35 \%(7 / 20)$ of tissue segments, all of which were scored
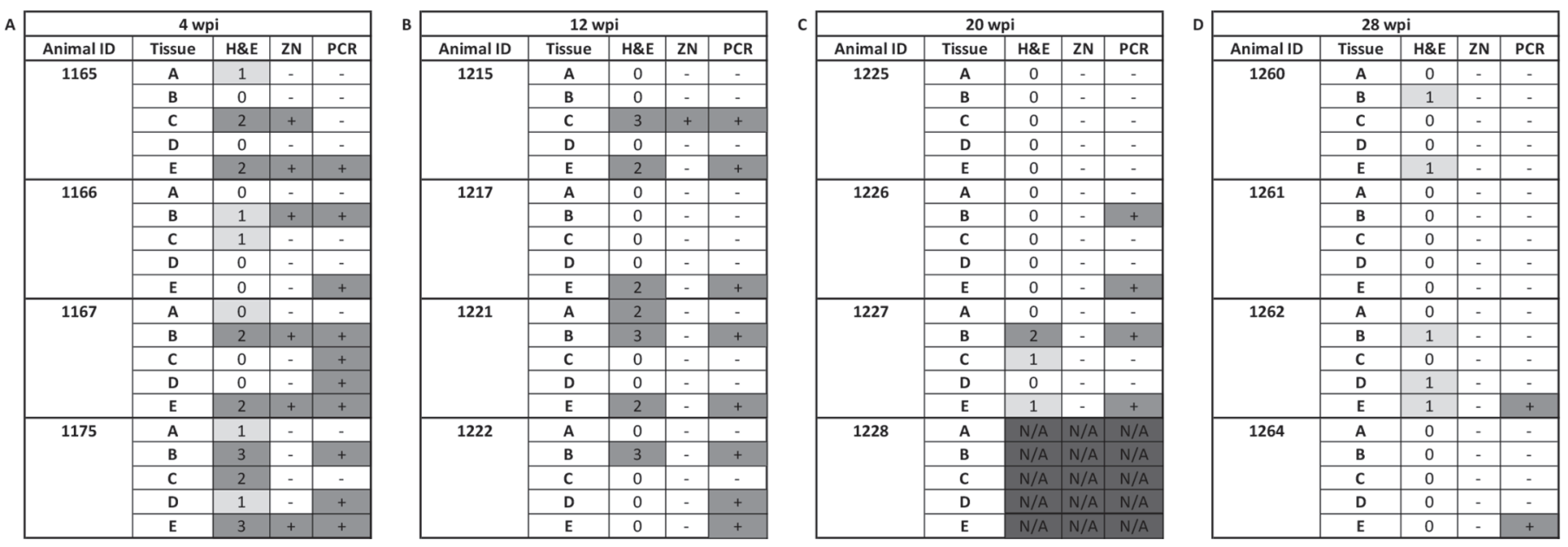

Figure 1. Histologic lesion scores (H \& E), Ziehl-Neelsen (ZN) data, and Mycobacterium avium ssp. paratuberculosis (MAP) PCR data for intestinal and lymph node tissue segments from monensin-supplemented, MAP-exposed calves. Histologic lesions were considered within normal limits (score of 0 ), mild (score of 1; light gray), or moderate (score of 2 or 3; dark gray). The ZN results were based on detection of acid-fast bacilli in the tissue segment (positives shown in dark gray). The PCR results were based on detection of MAP by PCR in the tissues (positives shown in dark gray). The 4 panels represent study time points at (A) 4, (B) 12, (C) 20, and (D) 28 wk postinoculation (wpi), with examination of 4 ileal tissues (A-D) and the ileocecal lymph node (E) for each animal. Calf 1228 at 20 wpi (panel C) was killed early and its data were discarded (N/A) from the study due to illness shortly after surgical MAP inoculation. 

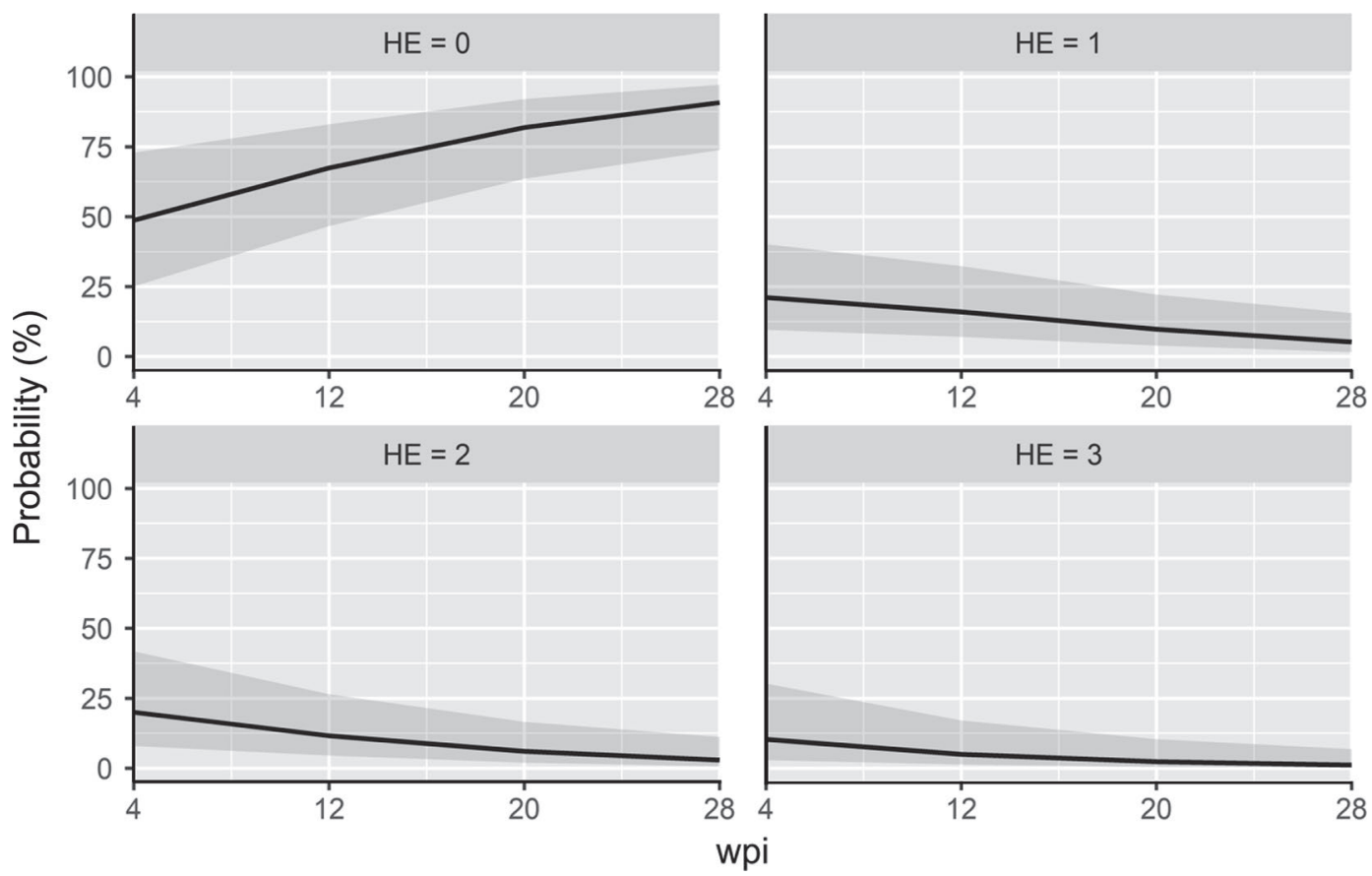

Figure 2. Marginal effects plot of the histologic lesion score statistical model depicting the probability of histologic lesion scores in Mycobacterium avium ssp. paratuberculosis (MAP)-exposed, monensin-supplemented calves as a factor of time in weeks postinoculation (wpi). The calculated probability is depicted as a solid line, and the $95 \%$ confidence interval is shown as the shaded region. The statistical model identified a significant protective effect of time on the predicted histologic lesion score, with an odds ratio of 0.46 (95\% CI: $0.28-0.76 ; P=0.002$ ). $\mathrm{HE}=$ hematoxylin and eosin.

as moderate lesions, and AFB were observed in 5\% $(1 / 20)$ of $\mathrm{ZN}$-stained tissue segments.

At 20 wpi, MAP-exposed calves had a median lesion score of 0 (range: 0-2), with 1 tissue scoring at the maximum lesion score of 2 . Lesions were observed in $20 \%(3 / 15)$ of tissue segments, with 2 mild lesions and 1 moderate lesion, and AFB were not observed in any of the $\mathrm{ZN}$-stained tissue segments.

At 28 wpi, MAP-exposed calves had a median lesion score of 0 (range: $0-1$ ), with 5 tissues scoring at the maximum lesion score of 1 . Lesions were observed in $25 \%(5 / 20)$ of tissues, all demonstrating mild lesions, and AFB were not observed in any of the $\mathrm{ZN}$-stained tissue segments.

There was a significant protective effect of time on predicted histologic lesion scores with an odds ratio of
$0.46(95 \% \mathrm{CI}=0.28-0.76 ; P=0.002)$, depicted as a marginal effects plot in Figure 2. For detection of AFB, the statistical model did not converge. This is likely largely due to the very small number of $\mathrm{ZN}$-positive tissues at time points other than the earliest time of 4 wpi. Therefore, statistical modeling to predict the probability of ZN-positive tissues over time was discarded from consideration in this study.

\section{Tissue PCR}

The PCR detection of MAP in intestinal tissues is summarized in Figure 1. At all time points, all sections of intestine and lymph node tissue segments from unexposed control calves tested negative for MAP by PCR. At 4 wpi, 50\% (10/20) of all tissues tested posi-

Table 1. Summary of histologic lesion scores and Ziehl-Neelsen (ZN)-positive tissues in monensin-supplemented calves exposed to Mycobacterium avium ssp. paratuberculosis by time point in weeks postinoculation (wpi)

\begin{tabular}{|c|c|c|c|c|c|c|}
\hline \multirow{2}{*}{$\begin{array}{l}\text { Time } \\
\text { point }\end{array}$} & \multicolumn{3}{|c|}{ No. of lesions } & \multirow{2}{*}{$\begin{array}{l}\text { Median lesion } \\
\text { score (range) }\end{array}$} & \multirow{2}{*}{$\begin{array}{l}\text { Maximum score } \\
\text { (no. observed) }\end{array}$} & \multirow{2}{*}{$\begin{array}{l}\text { No. ZN } \\
\text { positive }\end{array}$} \\
\hline & Mild & Moderate & Severe & & & \\
\hline 4 wpi & 5 & 7 & 0 & $1(0-3)$ & $3(2)$ & 6 \\
\hline 12 wpi & 0 & 7 & 0 & $0(0-3)$ & $3(3)$ & 1 \\
\hline $20 \mathrm{wpi}$ & 2 & 1 & 0 & $0(0-2)$ & $2(1)$ & 0 \\
\hline 28 wpi & 5 & 0 & 0 & $0(0-1)$ & $1(5)$ & 0 \\
\hline
\end{tabular}


tive for MAP by PCR. The number of positive tissues per calf varied between 1 and 4, with MAP detected in at least 1 tissue of every calf and in the draining lymph node of all MAP-exposed animals. At 12 wpi, $40 \%$ of all tissue segments tested positive for MAP by PCR. All MAP-exposed calves at this time point had between 1 and 3 positive tissue segments, and all of these calves tested positive for MAP by PCR in the draining lymph node. At 20 wpi, MAP was detected in $27 \%(4 / 15)$ of all tissues from MAP-exposed calves. One calf at 20 wpi had no MAP detectable by PCR in any tissue, whereas the other 2 calves were MAP positive by PCR in 2 tissues, including 1 section of intestine and 1 of draining lymph node. At 28 wpi, MAP was detected by PCR in only $10 \%(2 / 20)$ of all tissues from MAP-exposed calves. At this time point, only 2 of 4 calves had MAP detectable in any tissues, and in both of these calves MAP was detected in the draining ileocecal lymph node only. There was a significant protective effect of time on the probability of positive tissue MAP PCR segments, with an odds ratio of 0.12 (95\% CI $=0.02-0.67 ; P=0.016)$, shown as marginal effects plot (Figure 3 ).

\section{Fecal MAP PCR}

Results for detection of MAP in feces by PCR are shown in Figure 4. All unexposed control calves tested negative by fecal PCR at all time points throughout the study. Mycobacterium avium ssp. paratuberculosis was detected in feces of $10 \%(14 / 133)$ of all fecal samples from MAP-exposed calves, and 67\% (10/15) of all calves tested positive for MAP in feces by PCR at least once during the study, whereas $27 \%$ (4/15) tested positive in 2 consecutive samples. In the 4 -wpi group, MAP shedding was observed only in a single calf and only at a single time point. In the 12 -wpi group, all 4 animals tested positive for MAP in feces, with 2 of these animals showing consecutive shedding over 2 time points. In the 20-wpi group, 2 calves tested positive for MAP in feces, with 1 having consecutive shedding over 2 time points. Last, in the 28-wpi group, 3 of the calves had detectible fecal MAP, with 1 showing consecutive shedding over 2 time points and the latest incident of fecal shedding of MAP detected by PCR occurring at 8 wpi. Intermittent shedding was not detected in any of the MAP-exposed calves in this study.

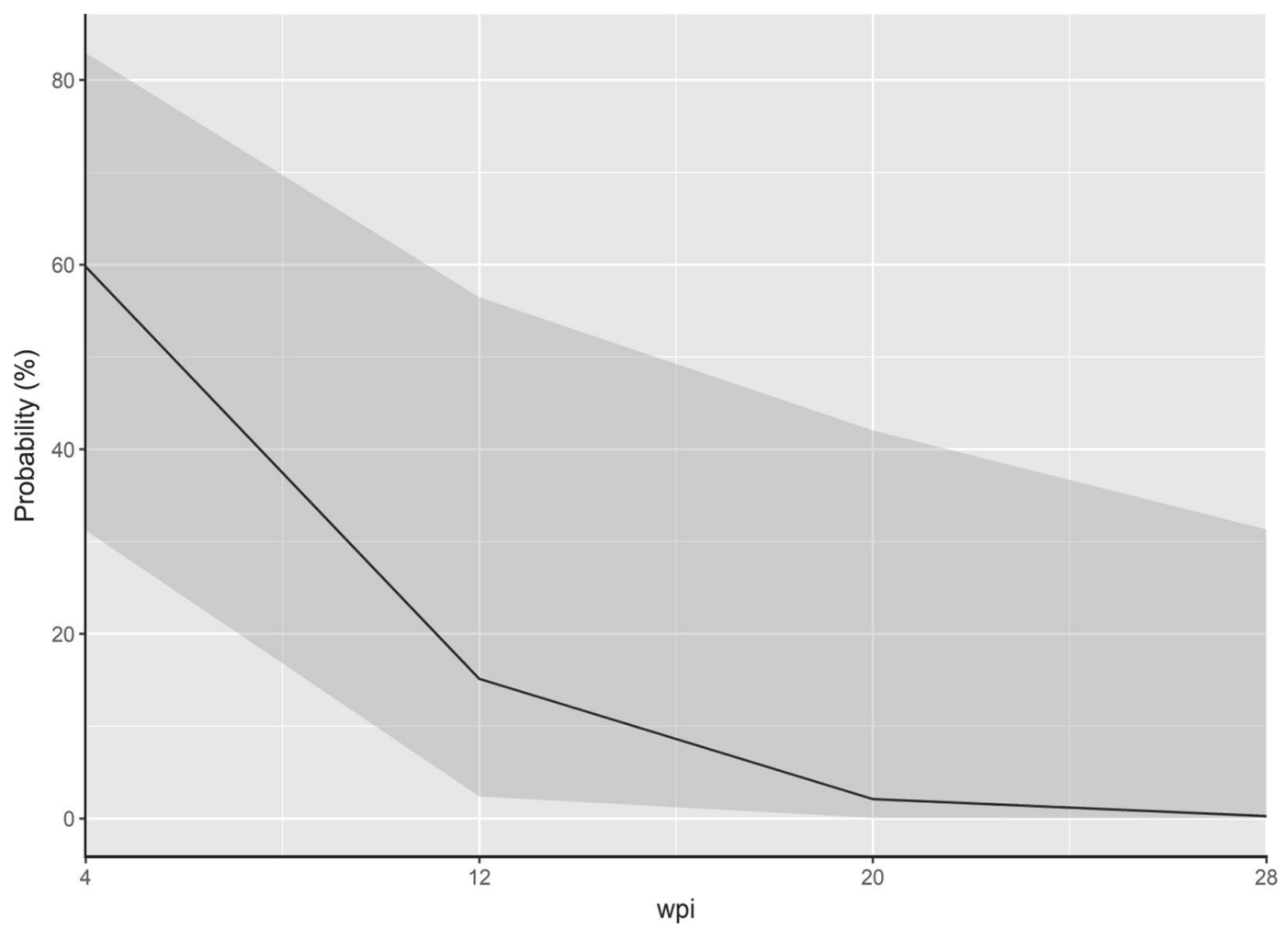

Figure 3. Marginal effects plot of the Mycobacterium avium ssp. paratuberculosis (MAP)-positive tissues by PCR statistical model depicting the probability of MAP-positive tissues in monensin-supplemented, MAP-exposed calves as a factor of time in weeks postinoculation (wpi). The calculated probability is depicted as a solid line, and the $95 \%$ confidence interval is shown as the shaded region. The statistical model identified a significant protective effect of time postinoculation on the probability of intestinal tissues testing positive for MAP by PCR with an odds ratio of 0.12 (95\% CI: $0.02-0.67 ; P=0.016)$. 


\section{Serum ELISA}

Detection of MAP-specific antibodies by commercial ELISA assay identified all MAP-exposed and control animals as negative. Sample:positive control ratios ranged from 0.00 to 0.077 , well below the manufacturer-recommended cut-off threshold of 0.45 , which is required for classification as suspect (Table 2).

\section{Animal Infection Status}

All MAP-exposed animals at 4 and 12 wpi were classified as MAP infected based on detection of the organism within tissue by PCR or ZN staining. All but 1 calf (calf ID 1166, 4 wpi) at these 2 time points were also classified as diseased based on the presence of moderate or severe MAP-induced granulomatous inflammation (score of 2 or greater) in at least 1 tissue section. At 20 wpi, 2 animals were classified as MAP infected; one of these was also classified as diseased, but the other calf had no detectable MAP in tissue and was thus classified as resilient. At 28 wpi, 2 calves were classified as MAP infected based on a single MAP-positive tissue section (lymph node) by PCR; however, the other 2 calves had no detectable MAP in any tissue and were thus classified as resilient.

\section{Effects of Monensin}

Data from monensin-supplemented calves were then compared with data from the monensin-free calf cohort
Table 2. Mycobacterium avium ssp. paratuberculosis (MAP)-specific serum ELISA

\begin{tabular}{llcc}
\hline $\begin{array}{l}\text { Infection } \\
\text { group }^{1}\end{array}$ & Animal ID & S/P ratio & \\
\hline 4 wpi & 1165 & 0 & Result \\
& 1166 & 0 & Neg \\
& 1167 & 0.006 & Neg \\
12 wpi & 1175 & 0.005 & Neg \\
& 1215 & 0.077 & Neg \\
& 1217 & 0.035 & Neg \\
20 wpi & 1221 & 0.052 & Neg \\
& 1222 & 0.016 & Neg \\
& 1225 & 0.004 & Neg \\
28 wpi & 1226 & 0.026 & Neg \\
& 1227 & 0.034 & Neg \\
& 1228 & NA & NA \\
& 1260 & 0.05 & Neg \\
& 1261 & 0.066 & Neg \\
& 1262 & 0.017 & Neg \\
& 1264 & 0.02 & Neg \\
\hline
\end{tabular}

${ }^{1}$ wpi $=$ weeks postinoculation.

${ }^{2}$ Sample:positive control ratio of the commercial ELISA assay of serum of monensin-supplemented MAP-exposed calves. A ratio below 0.45 is considered negative, 0.45 to 0.55 is suspect, and greater than 0.55 is positive.

${ }^{3} \mathrm{Neg}=$ negative.

${ }^{4} \mathrm{NA}=$ not available. Animal 1228 died during the study and thus was not available for the final time period. Animal 1228 has been retained here and throughout the paper for completeness.

(previously published in Stinson et al., 2018, as a description of the model) to investigate the effects of oral monensin sodium on MAP persistence in tissue and markers of infection in this model. Table 3 summarizes the PCR, ZN, and hematoxylin and eosin data from
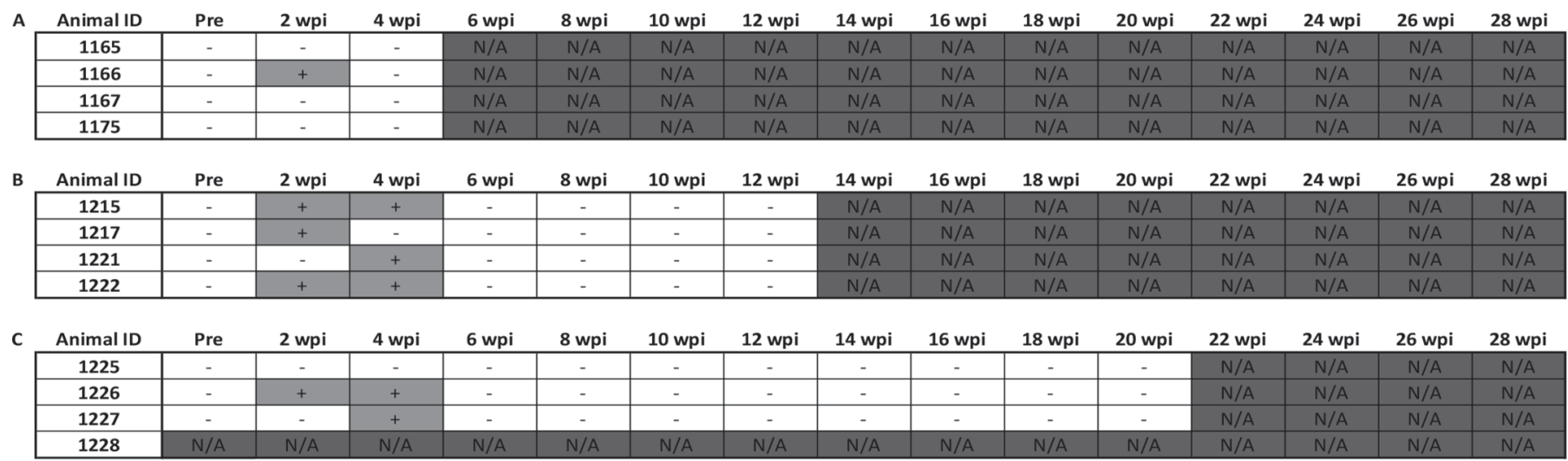

\begin{tabular}{|c|c|c|c|c|c|c|c|c|c|c|c|c|c|c|c|}
\hline Animal ID & Pre & $2 \mathrm{wpi}$ & $4 \mathrm{wpi}$ & 6 wpi & $8 \mathrm{wpi}$ & 10 wpi & 12 wpi & 14 wpi & 16 wpi & 18 wpi & 20 wpi & $22 \mathrm{wpi}$ & 24 wpi & 26 wpi & $28 \mathrm{wpi}$ \\
\hline 1260 & - & - & - & + & - & - & - & - & - & - & - & - & - & - & - \\
\hline 1261 & - & - & - & + & + & - & - & - & - & - & - & - & - & - & - \\
\hline 1262 & - & - & - & - & - & - & - & - & - & - & - & - & - & - & - \\
\hline 1264 & - & - & - & - & + & - & - & - & - & - & - & - & - & - & - \\
\hline
\end{tabular}

Figure 4. The PCR detection of Mycobacterium avium ssp. paratuberculosis (MAP) in feces of monensin-supplemented, MAP-exposed calves by weeks postinoculation (wpi). Panels show calves at time points (A) 4, (B) 12, (C) 20, and (D) 28 wpi; preinoculation (Pre) and biweekly samples are also shown. Positive results are highlighted in gray, and unmeasured time points are marked as N/A and shaded dark gray. Calf 1228 in the 20-wpi group (panel C) was killed due to illness shortly after inoculation and was excluded from the trial. 
Table 3. Comparison of histologic lesions, Ziehl-Neelsen (ZN) data, Mycobacterium avium ssp. paratuberculosis PCR data, and animal infection status between the monensin-supplemented calves and monensin-free calves (from Stinson et al., 2018)

\begin{tabular}{|c|c|c|c|c|c|c|}
\hline Group & Time point $^{1}$ & $\begin{array}{l}\text { Median lesion } \\
\text { score (range) }\end{array}$ & $\begin{array}{l}\text { No. of lesions } \\
\text { (any grade) }\end{array}$ & $\begin{array}{l}\text { No. of ZN- } \\
\text { positive tissues }\end{array}$ & $\begin{array}{l}\text { No. of PCR- } \\
\text { positive tissues }\end{array}$ & $\begin{array}{c}\text { Infection } \\
\text { status }^{2}\end{array}$ \\
\hline \multirow[t]{2}{*}{ Monensin supplemented } & 4 wpi & $1(0-3)$ & 12 & 6 & 10 & $3 / 1 / 0$ \\
\hline & 28 wpi & $0(0-1)$ & 5 & 0 & 2 & $0 / 2 / 2$ \\
\hline \multirow{2}{*}{ Monensin free } & 4 wpi & $0(0-2)$ & 5 & 3 & 13 & $2 / 2 / 0$ \\
\hline & 12 wpi & $1(0-3)$ & 11 & 5 & 10 & $2 / 2 / 0$ \\
\hline
\end{tabular}

${ }^{1} \mathrm{wpi}=$ weeks postinoculation.

${ }^{2}$ Infection status is shown as number of diseased animals, infected animals with no evidence of disease, and resilient animals, as described (formatted as diseased/infected/resilient).

${ }^{3}$ One animal in the 20 wpi group was killed early and removed from the study due to illness. As such, there is a maximum of 15 tissues at this time point versus 20 tissues in all others time points.

both cohorts by time point along with animal infection classification (diseased, infected with no evidence of disease, resilient). Statistically, monensin supplementation had no significant effect on predicted histologic lesion scores $(P=0.520)$, the probability of detecting AFB by ZN staining $(P=0.336)$, or the probability of tissues testing positive for MAP by PCR $(P=0.177)$. The statistical analyses of data from both cohorts, analyzed independently and then combined, are summarized and presented in Table 4.

\section{DISCUSSION}

Johne's disease poses several challenges with regards to prevention and control measures within affected herds. Diagnostic methods with poor sensitivity, especially during subclinical disease, make identification of infected animals difficult. Vaccination has shown partial success in reducing fecal MAP shedding but still fails to prevent infection; therefore, alternative approaches to aiding producers with management of MAP infection on farms are needed. With in vivo and in vitro evidence supporting putative beneficial effects of oral monensin sodium against MAP infection in cattle, we set out to use an experimental model of intestinal MAP infection to investigate the effects of oral monensin supplementation of young calves on persistence of MAP within tissues, MAP-induced lesions, fecal MAP shedding, and MAP-specific antibody responses. We hypothesized that oral monensin supplementation of young calves during the early phases of experimental intestinal MAP infection would reduce tissue colonization of MAP and thus reduce the severity of lesions, fecal MAP shedding, and MAP-specific antibody responses and improve overall host resilience to MAP infection.

This article focuses on the monensin-supplemented cohort, which we then compared directly with data from the monensin-free cohort of the same study, which were previously published as outcomes of MAP infection in the direct Peyer's patch MAP-inoculation model over a period of 28 wk (Stinson et al., 2018). Collectively, data from our direct MAP inoculation model are similar to the findings of a recent 5-yr oral MAP exposure study in cattle in which the cattle demonstrated resilience

Table 4. Summary of statistical model results for the monensin-free calves and monensin-supplemented calves (from Stinson et al., 2018)

\begin{tabular}{|c|c|c|c|c|c|c|c|c|c|c|}
\hline \multirow[b]{2}{*}{ Group } & \multirow[b]{2}{*}{ Effect $^{1}$} & \multicolumn{3}{|c|}{ Histologic lesion score ${ }^{2}$} & \multicolumn{3}{|c|}{$\mathrm{ZN}$} & \multicolumn{3}{|c|}{ MAP PCR } \\
\hline & & $\begin{array}{c}\text { Odds } \\
\text { ratio }\end{array}$ & $95 \% \mathrm{CI}$ & $P$-value & $\begin{array}{l}\text { Odds } \\
\text { ratio }\end{array}$ & $95 \% \mathrm{CI}$ & $P$-value & $\begin{array}{l}\text { Odds } \\
\text { ratio }\end{array}$ & $95 \% \mathrm{CI}$ & $P$-value \\
\hline Monensin supplemented & Time point & 0.46 & $0.28-0.76$ & $0.002^{*}$ & & $\mathrm{NA}^{3}$ & & 0.12 & $0.02-0.67$ & $0.016^{*}$ \\
\hline Monensin free & Time point & 1.07 & $0.71-1.60$ & 0.743 & 0.61 & $0.33-1.14$ & 0.120 & 0.36 & $0.18-0.70$ & $0.003^{*}$ \\
\hline \multirow[t]{2}{*}{ Combined } & Time point & 0.75 & $0.55-1.01$ & 0.060 & 0.42 & $0.24-0.74$ & $0.002^{*}$ & 0.32 & $0.18-0.58$ & $<0.001^{*}$ \\
\hline & Monensin & 1.04 & $0.55-1.99$ & 0.900 & 0.60 & $0.21-1.70$ & 0.336 & 0.57 & $0.25-1.29$ & 0.177 \\
\hline
\end{tabular}

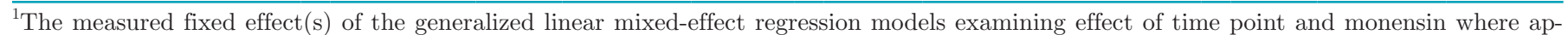
plicable.

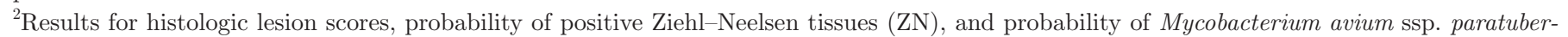
culosis PCR-positive tissues (MAP PCR).

${ }^{3}$ The model failed to converge and thus was excluded from the trial.

*Finding is statistically significant. 
and recovery from MAP infection (Begg et al., 2018). As summarized in Table 3, calves in both monensin-free and monensin-supplemented cohorts demonstrated apparent localized clearance of MAP, which is characterized by significantly reduced probability of tissues testing positive for MAP by PCR over time; however, there were no significant changes in predicted histologic lesion scores or number of ZN-positive tissues. Interestingly, we also observed that monensin-supplemented calves demonstrated resilience to MAP infection 8 wk earlier compared with monensin-free calves (20 wpi compared with 28 wpi). One calf at 28 wpi in the monensin-free cohort demonstrated evidence of progression to subclinical disease, characterized by the presence of MAP by PCR and MAP-induced inflammation in multiple segments of the intestine and draining lymph node as well as evidence of seroconversion based on the commercial serum MAP antibody ELISA. Comparatively, none of the monensin-supplemented calves at 28 wpi showed any evidence of disease, and no monensinsupplemented calf at any time point showed evidence of seroconversion.

Monensin-supplemented calves had a comparatively greater number of histologic lesions and higher histologic lesion scores at 4 wpi compared with monensinfree calves (Table 3). Furthermore, we observed a significant reduction in predicted histologic lesion scores as an effect of time in the monensin-supplemented calves but not in the monensin-free calves (Table 4). The reduction of MAP in tissues, as evidenced by the PCR results, was statistically significant in both cohorts, with comparable protective effects of time in both monensin-free and monensin-supplemented calves. Fecal MAP shedding was similar overall between the 2 cohorts with a few minor differences. The monensinsupplemented calves had a greater number of positive fecal samples ( $10 \%$ vs. $7 \%$ ); however, no MAP was detected in feces after 8 wpi, whereas we detected MAP shedding by PCR in the monensin-free calves at 12 wpi (Stinson et al., 2018). Despite these differences, we found no statistically significant effect of monensin on any of the outcomes of infection in our model, including PCR, ZN, or predicted histologic lesion scores.

In summary, this preliminary study examining the effects of oral monensin supplementation on early enteric MAP infection in calves identified several differences in progression and outcomes following experimental MAP inoculation, though no specific and significant effect of monensin was observed. This highlights a significant limitation of this study: that the small group sizes may have negatively affected our ability to identify other important differences between the 2 groups due to greater interanimal variance than anticipated. One key finding that requires further investigation was that resilience was observed $8 \mathrm{wk}$ earlier in the monensinsupplemented calves compared with the monensin-free cohort; however, evidence is insufficient to conclude whether this finding was attributable to monensin supplementation or simply a result of high interanimal variance of responses.

\section{ACKNOWLEDGMENTS}

This work could not have been completed without the support of the staff of the University of Guelph (Guelph, ON, Canada) animal isolation facility, central animal facility, and Ponsonby dairy research station. We also thank the undergraduate and DVM students who volunteered their time assisting with sample collection and processing work. In addition, special thanks to Sarah Schorno (Department of Integrative Biology) and Ryan Horricks (Department of Pathobiology), University of Guelph, Ontario, Canada, for their insight in developing the statistical inference methods used in this study. This research was supported in part by Elanco Animal Health Canada (Guelph, ON, Canada) as a grant-in-aid. Elanco provided advice during study planning and drafting of the manuscript but not with data collection or analysis.

\section{REFERENCES}

Bastida, F., and R. A. Juste. 2011. Paratuberculosis control: A review with a focus on vaccination. J. Immune Based Ther. Vaccines 9:8. https://doi.org/10.1186/1476-8518-9-8.

Bates, D., M. Maechler, B. Bolker, and S. Walker. 2015. Fitting linear mixed-effect models using lme4. J. Stat. Softw. 67:1-48. https:/ doi.org/10.18637/jss.v067.i01

Begg, D. J., K. M. Plain, K. de Silva, R. Gurung, A. Gunn, A. C. Purdie, and R. J. Whittington. 2018. Immunopathological changes and apparent recovery from infection revealed in cattle in an experimental model of Johne's disease using a lyophilised culture of Mycobacterium avium subspecies paratuberculosis. Vet. Microbiol. 219:53-62. https://doi.org/10.1016/j.vetmic.2018.03.029.

Brumbaugh, G. W., J. F. Edwards, A. J. Roussel, and T. D. Thomson. 2000. Effect of monensin sodium on histological lesions of naturally occurring bovine paratuberculosis. J. Comp. Pathol. 123:22-28. https://doi.org/10.1053/jcpa.1999.0381.

Brumbaugh, G. W., P. F. Frelier, A. J. Roussel, and T. D. Thomson. 1992. Prophylactic effect of monensin sodium against experimentally induced paratuberculosis in mice. Am. J. Vet. Res. 53:544546.

Brumbaugh, G. W., R. B. Simpson, J. F. Edwards, D. R. Anders, and T. D. Thomson. 2004. Susceptibility of Mycobacterium avium sbsp paratuberculosis to monensin sodium or tilmicosin phosphate in vitro and resulting infectivity in a murine model. Can. J. Vet. Res. 68:175-181.

Christensen, R. H. B. 2019. Ordinal-regression models for ordinal data. R package version 2019. 4-25. http://www.cran.r-project .org $/$ package $=$ ordinal $/$.

Collins, M. T. 1994. Clinical approach to control of bovine paratuberculosis. J. Am. Vet. Med. Assoc. 204:208-210.

de Silva, K., K. Plain, A. Purdie, D. Begg, and R. Whittington. 2018. Defining resilience to mycobacterial disease: Characteristics of survivors of ovine paratuberculosis. Vet. Immunol. Immunopathol. 195:56-64. https://doi.org/10.1016/j.vetimm.2017.11.008. 
Duffield, T. F., K. E. Leslie, D. Sandals, K. Lissemore, B. W. McBride, J. H. Lumsden, P. Dick, and R. Bagg. 1999a. Effect of prepartum administration of monensin in a controlled-release capsule on milk production and milk components in early lactation. J. Dairy Sci. 82:272-279. https://doi.org/10.3168/jds.S0022-0302(99)75233-1.

Duffield, T. F., K. E. Leslie, D. Sandals, K. Lissemore, B. W. McBride, J. H. Lumsden, P. Dick, and R. Bagg. 1999b. Effect of a monensincontrolled release capsule on cow health and reproductive performance. J. Dairy Sci. 82:2377-2384. https://doi.org/10.3168/jds .S0022-0302(99)75488-3.

Fecteau, M.-E., and R. H. Whitlock. 2011. Treatment and chemoprophylaxis for paratuberculosis. Vet. Clin. North Am. Food Anim. Pract. 27:547-557. https://doi.org/10.1016/j.cvfa.2011.07.002.

Garry, F. 2011. Control of paratuberculosis in dairy herds. Vet. Clin. North Am. Food Anim. Pract. 27:599-607. https://doi.org/10 .1016/j.cvfa.2011.07.006.

Goodrich, R. D., J. E. Garrett, D. R. Gast, M. A. Kirick, D. A. Larson, and J. C. Meiske. 1984. Influence of monensin on the performance of cattle. J. Anim. Sci. 58:1484-1498.

Greenstein, R. J., L. Su, R. H. Whitlock, and S. T. Brown. 2009. Monensin causes dose dependent inhibition of Mycobacterium avium subspecies paratuberculosis in radiometric culture. Gut Pathog. 1:4. https://doi.org/10.1186/1757-4749-1-4.

Hendrick, S. H., T. F. Duffield, K. E. Leslie, K. D. Lissemore, M. Archambault, R. Bagg, P. Dick, and D. F. Kelton. 2006a. Monensin might protect Ontario, Canada dairy cows from paratuberculosis milk-ELISA positivity. Prev. Vet. Med. 76:237-248. https://doi .org/10.1016/j.prevetmed.2006.05.007.

Hendrick, S. H., D. F. Kelton, K. E. Leslie, K. D. Lissemore, M. Archambault, R. Bagg, P. Dick, and T. F. Duffield. 2006b. Efficacy of monensin sodium for the reduction of fecal shedding of $M y$ cobacterium avium ssp. paratuberculosis in infected dairy cattle. Prev. Vet. Med. 75:206-220. https://doi.org/10.1016/j.prevetmed 2006.03.001.

Juste, R. A., M. Alonso-Hearn, E. Molina, M. Geijo, P. Vazquez, I. A. Sevilla, and J. M. Garrido. 2009. Significant reduction in bacterial shedding and improvement in milk production in dairy farms after the use of a new inactivated paratuberculosis vaccine in a field trial. BMC Res. Notes 2:233. https://doi.org/10.1186/1756 $-0500-2-233$

Köhler, H., H. Gyra, K. Zimmer, K. G. Dräger, B. Burkert, B. Lemser, D. Hausleithner, K. Cubler, W. Klawonn, and R. G. Hess. 2001. Immune reactions in cattle after immunization with a Mycobacterium paratuberculosis vaccine and implications for the diagnosis of M. paratuberculosis and M. bovis infections. J. Vet. Med. B Infect. Dis. Vet. Public Health 48:185-195.

McDougald, L. R. 1978. Monensin for the prevention of coccidiosis in calves. Am. J. Vet. Res. 39:1748-1749.
McKenna, S. L. B., G. P. Keefe, A. Tiwari, J. VanLeeuwen, and H. W. Barkema. 2006. Johne's disease in Canada part II: Disease impacts, risk factors, and control programs for dairy producers. Can. Vet. J. 47:1089-1099.

Muskens, J., F. van Zijderveld, A. Eger, and D. Bakker. 2002. Evaluation of the long-term immune response in cattle after vaccination against paratuberculosis in two Dutch dairy herds. Vet. Microbiol. 86:269-278.

Plattner, B. L., Y.-W. Chiang, J. A. Roth, R. Platt, E. Huffman, J. Zylstra, and J. M. Hostetter. 2011. Direct inoculation of Mycobacterium avium subspecies paratuberculosis into ileocecal Peyer's patches results in colonization of the intestine in a calf model. Vet. Pathol. 48:584-592. https://doi.org/10.1177/0300985810383874.

Stabel, J. R., W. R. Waters, J. P. Bannantine, and K. Lyashchenko. 2011. Mediation of host immune responses after immunization of neonatal calves with a heat-killed Mycobacterium avium ssp. paratuberculosis vaccine. Clin. Vaccine Immunol. 18:2079-2089. https: //doi.org/10.1128/CVI.05421-11.

Stinson, K. J., M. M. Baquero, and B. L. Plattner. 2018. Resilience to infection by Mycobacterium avium subspecies paratuberculosis following direct intestinal inoculation in calves. Vet. Res. 49:58. https://doi.org/10.1186/s13567-018-0553-7.

Sweeney, R. W. 2011. Pathogenesis of paratuberculosis. Vet. Clin. North Am. Food Anim. Pract. 27:537-546. https://doi.org/10 .1016/j.cvfa.2011.07.001

Sweeney, R. W., M. T. Collins, A. P. Koets, S. M. McGuirk, and A. J. Roussel. 2012. Paratuberculosis (Johne's disease) in cattle and other susceptible species. J. Vet. Intern. Med. 26:1239-1250. https: //doi.org/10.1111/j.1939-1676.2012.01019.x.

Sweeney, R. W., R. H. Whitlock, T. L. Bowersock, D. L. Cleary, T. R. Meinert, P. L. Habecker, and G. W. Pruitt. 2009. Effect of subcutaneous administration of a killed Mycobacterium avium subsp paratuberculosis vaccine on colonization of tissues following oral exposure to the organism in calves. Am. J. Vet. Res. 70:493-497. https://doi.org/10.2460/ajvr.70.4.493.

Tiwari, A.. J. A. VanLeeuwen, S. L. B. McKenna, G. P. Keefe, and H. W. Barkema. 2006. Johne's disease in Canada Part I: Clinical symptoms, pathophysiology, diagnosis, and prevalence in dairy herds. Can. Vet. J. 47:874-882.

Uzonna, J. E., P. Chilton, R. H. Whitlock, P. L. Habecker, P. Scott, and R. W. Sweeney. 2003. Efficacy of commercial and field-strain Mycobacterium paratuberculosis vaccinations with recombinant IL12 in a bovine experimental infection model. Vaccine 21:3101-3109.

Whittington, R. J., D. J. Begg, K. de Silva, A. C. Purdie, N. K. Dhand, and K. M. Plain. 2017. Case definition terminology for paratuberculosis (Johne's disease). BMC Vet. Res. 13. https://doi .org/10.1186/s12917-017-1254-6. 